\title{
Effects of sleeve gastrectomy on parameters of lipid and glucose metabolism in obese women -6 months after operation
}

\author{
Marek Bužga ${ }^{1}$, Pavol Holéczy², Zdeněk Švagera ${ }^{3}$, Pavol Švorc Jr ${ }^{1}$, Vladislava Zavadilová ${ }^{1}$ \\ 1Department of Physiology, Faculty of Medicine, University of Ostrava, Czech Republic \\ 2Department of Surgical Disciplines, Faculty of Medicine, University of Ostrava, Czech Republic \\ ${ }^{3}$ Department of Biomedicine Disciplines, Faculty of Medicine, University of Ostrava, Czech Republic
}

Videosurgery Miniinv 2013; 8 (1): 22-28

DOI: $10.5114 /$ wiitm.2011.31631

\begin{abstract}
Introduction: Surgical intervention in obesity is today the most effective treatment method in high level obesity management with long-term clinical results and satisfaction of operated patients. Bariatric interventions not only ensure body weight reduction, but may influence lipid and saccharide metabolism as well.

Aim: To monitor the dynamics of changes in selected lipid and glucose metabolism parameters after laparoscopic sleeve gastrectomy (LSG) in obese women.

Material and methods: During the period from September 2010 to June 2011, 35 women, operated on by sleeve gastrectomy, were monitored within a pilot open study. Parameters of lipid and glucose metabolism were measured, and body composition was evaluated, using dual X-ray absorptiometry (DXA). Laboratory parameters were assessed prior to LSG and at 3 and 6 months after the surgery.

Results: Data of the 35 study subjects are presented. Average age was 41.9 years (27-68 years). Six months after LSG, body weight reduction was achieved from $117.7 \pm 17.1 \mathrm{~kg}$ to $91.2 \pm 17.2 \mathrm{~kg}(p<0.001)$. The body mass index (BMI) dropped from $42.7 \pm 4.7 \mathrm{~kg} / \mathrm{m}^{2}$ to $33.0 \pm 4.9 \mathrm{~kg} / \mathrm{m}^{2}(p<0.001)$. The excess weight loss (EWL) was $49.01 \%$. High density lipoprotein (HDL) cholesterol increased from $1.29 \mathrm{mmol} / \mathrm{l}$ to $1.39 \mathrm{mmol} / \mathrm{l}(p<0.025)$. Triacylglycerols dropped from $1.97 \mathrm{mmol} / \mathrm{l}$ to $1.31 \mathrm{mmol} / \mathrm{l}(p<0.001)$. Glycated hemoglobin dropped from $4.03 \%$ to $3.59 \%(p<0.001)$, and C-peptide decreased from $1703 \mathrm{pmol} / \mathrm{l}$ to $1209 \mathrm{pmol} / \mathrm{l}(p<0.002)$. The observed changes of low density lipoprotein (LDL) cholesterol, total cholesterol or fasting glucose levels were not significant. Six months after LSG, both weight and BMI significantly decreased.

Conclusions: Six months after the operation, glucose homeostasis was improved. Despite the rather short-term monitoring period, our study did confirm LSG to influence not only total weight loss and fat tissue reduction but to improve risk factors, mainly glucose homeostasis and dyslipidemia, as well.
\end{abstract}

Key words: bariatric surgery, morbid obesity, cholesterol, glycemia, laparoscopy, sleeve gastrectomy.

\section{Introduction}

The rapidly increasing prevalence of obesity observed in recent decades is a major public health problem of pandemic nature [1]. According to forecasts, there will be 2.3 billion overweight adults and more than 700 million people suffering from obesity worldwide by the year 2015 [2]. In the countries of Central and Eastern Europe, including the Czech Republic, the prevalence of obesity is a forefront issue in all epidemiological studies. Results of the latest large epidemiological study conducted in the 
Czech Republic reveal $30 \%$ of Czechs to be overweight and $25 \%$ as suffering from obesity. It is an alarming fact that, during the last 6 years only, the number of obese subjects has increased by $5 \%$ in the total population of 10.3 million, which makes 425,000 people [3]. Recently, a series of epidemiologic studies has evidenced a close link between morbid obesity and type 2 diabetes mellitus, hypertension, hyperlipidemia, obstructive sleep apnea, metabolic syndrome and insulin resistance $[4,5]$. The scale of the problem is also confirmed by the fact that obesity, when exceeding $40 \mathrm{~kg} / \mathrm{m}^{2}$, shortens life span, on average, by 20 years, while obesity consequences are more severe than the consequences of tobacco smoking or alcohol consumption [6, 7].

The treatment of obese patients is a demanding and long-term undertaking, in which there are no 'short cuts' or 'quick fixes'. Literature data clearly show that no weight loss after pharmacotherapy or diet therapy remains effective in the long run [8]. Today, surgical treatment of higher obesity levels is undoubtedly the most effective procedure with the best outcomes in a long-term perspective. Dramatic weight loss leads to improvement of associated comorbidities as well $[9,10]$. The results of studies published in the last decade have demonstrated that weight reduction by $35-40 \%$ following surgical intervention treatment of obesity may be regarded as permanent, as it is maintained for more than 5 years [11]. At the same time, a significant improvement of hypertension and dyslipidemia [12], as well as remissions of type 2 diabetes mellitus, have been reported [13, 14].

According to mandatory European interdisciplinary recommendations for surgical treatment of obesity, bariatric surgical interventions to limit the quantity of consumed food as a result of gastric capacity reduction (restrictive methods) comprise the following methods: vertical banded gastroplasty (VBG), laparoscopic sleeve gastrectomy (LSG), adjustable gastric banding (AGB) and gastric bypass (GBP). Laparoscopic intervention is considered the first choice therapy among bariatric procedures [15], similarly as in other types of complex gastric surgery [16]. Laparoscopic sleeve gastrectomy (LSG) is one of the restrictive bariatric methods [17]. For the first time, sleeve gastrectomy (SG) was described by Hess and Hess [18] and then, successively, by Marceau et al. [19] as a modification of Scopinaro's technique of biliopancreatic diversion (BPD). Originally, LSG was performed as a first-stage procedure before Roux-Y- bypass or biliopancreatic diversion with duodenal switch in high-risk patients. Considering its low risk and easier technique, LSG was accepted as the primary bariatric procedure, even more when it became clear that its effects are satisfactory in many patients. In 2003, laparoscopic sleeve gastrectomy was accepted as a first-choice surgical intervention for patients suffering from super obesity (body mass index (BMI) exceeding $50 \mathrm{~kg} / \mathrm{m}^{2}$ ) [20]. The positive effects of LSG in obesity treatment include not only food intake control as a consequence of reduced gastric volume but also its influence, targeting certain hormones in the gastrointestinal tract, such as glucagon-like peptide (GLP), peptide $Y$ (PYY) and ghrelin, which controls energy metabolism [21, 22].

\section{Aim}

The aim of the reported study was to monitor the dynamics of changes in selected parameters of lipid and glucose metabolism after sleeve gastrectomy (LSG) in obese women.

\section{Material and methods}

During the period from September to December 2010, 78 patients, aged 27-50 years, were operated on within an open prospective clinical pilot study, undertaken to monitor the metabolic responses of lipid and bone tissue, including weight reduction, after LSG. This report presents the results of 35 examined female patients in 6 months after the operation. The accepted criteria for surgical treatment took into account the guidelines issued by the International Federation for the Surgery of Obesity and Metabolic Disorders (IFSO) [23], i.e. individuals with $\mathrm{BMI} \geq 40 \mathrm{~kg} / \mathrm{m}^{2}$ or $\mathrm{BMI} \geq 35 \mathrm{~kg} / \mathrm{m}^{2}$ with comorbidities. The study was approved by the Ethical Committee at the Faculty of Medicine, the University of Ostrava. Patients were operated on at two bariatric centers of Ostrava medical facilities. The exclusion criteria included thyroid gland disease, diseases of the digestive system associated with impaired intestinal resorption, disorders of renal functions, diabetes mellitus and hypolipidemic treatment. Four weeks before the planned intervention, body composition was examined in all the probands by the dual-emission X-ray absorptiometry (DXA) method (Discovery W, Hollogic, USA). At the same time, venipuncture was performed (morning hours, fasting). Blood samples were processed for subsequent analysis within $20 \mathrm{~min}$ 


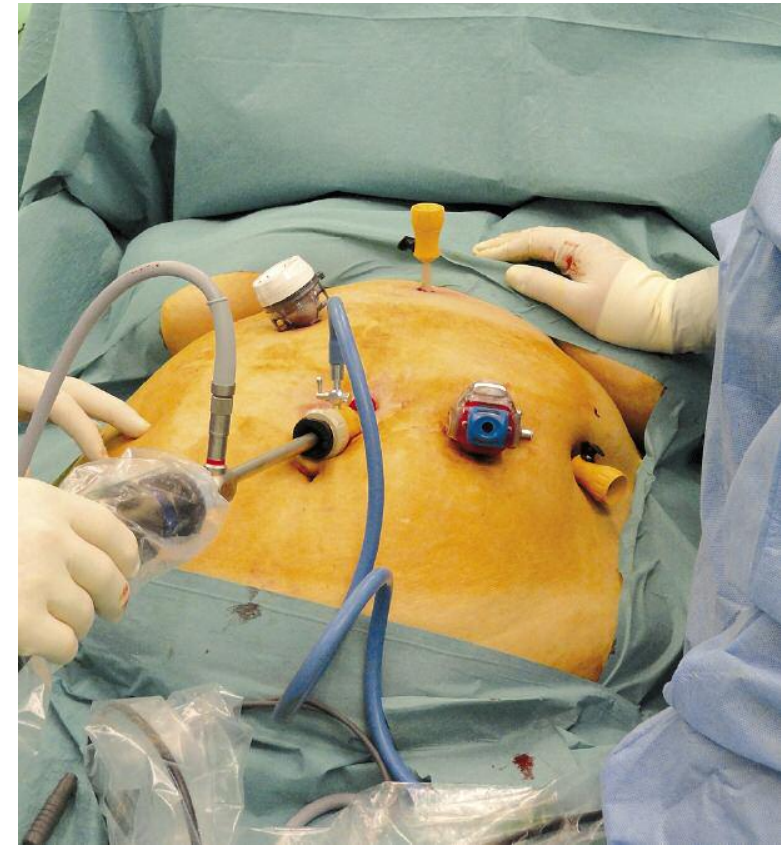

Photo 1. Trocar placement for laparoscopic sleeve gastrectomy

after venipuncture. Serum concentrations of the following substances were assayed: glucose, triacylglycerols (TG), total cholesterol (TC), followed by HDL and LDL cholesterol (AU 5420, Beckman Coulter, Inc., USA). Glycated hemoglobin $\left(\mathrm{HbA}_{1 \mathrm{c}}\right)$ was determined by the ion exchange chromatography method in Tosoh G8 apparatus (Tosoh Corporation, Japan) and by the RIA C-peptide method. With all the results at hand, surgical sleeve gastrectomy was performed. At 3 and 6 months after the surgery, the treated individuals were invited for a follow-up with DXA and collected blood samples.

\section{Statistical analysis}

Paired $t$-test was used to analyze the differences between results obtained before sleeve gastrectomy and 6 months after. All the statistical tests were evaluated at the significance level of $5 \%$. A $p$ value of $<0.05$ was considered statistically significant. All descriptive statistics and tests were performed using the R software (R Development Core Team 2011).

\section{Operation technique}

The operation was performed in general anesthesia in the supine position. In the course of the operation, the operation table was tilted to allow optimal access to the operation field. Pneumoperitoneum was done by a Veress needle. The first trocar was placed blind, while the others were located under visual control. A 30-degree laparoscope was used. Trocar placement is shown in Photo 1.

Following a routine revision of the abdominal cavity, the area of the diaphragmatic hiatus was revised in detail. If hiatus hernia was found, hiatoplasty was performed. The next step involved mobilization of the greater stomach curvature, which started $4 \mathrm{~cm}$ proximally from the pylorus. That step was accomplished with an ultrasound dissector (Harmonic Ace, Johnson and Johnson, Cincinnati, USA). The mobilization stretched as far as to the left diaphragmatic crus. Following satisfactory mobilization, the stomach was longitudinally resected with an Echelon endoscopic stapler (Johnson and Johnson, Cincinnati, USA) with blue, $60 \mathrm{~mm}$ long cartridges. The size of the left stomach space was limited by an anatomic border the end of the short gastric vessels from the lesser curvature of the stomach. In that phase of the operation, no calibration bougie was applied, nor was any reinforcement of the resection line used. The resection line was not oversewn. The resected stomach was extracted following some dilation of the excision in the left mesogastrium, without using a plastic bag. If necessary, a Redon drain was subhepatically introduced into the left subphrenic space through the epigastric incision at the end of the operation. Trocars were extracted under visual control and the pneumoperitoneum was removed. The procedure was finished by suture of the skin; no sutures of the muscular fascia were applied.

\section{Results}

The average age of women included in the study was $41.89 \pm 10.21$ years (27-68 years). The average weight in the whole group at the beginning of the study was $117.69 \pm 17.05 \mathrm{~kg}(95-160 \mathrm{~kg})$. The average body mass index was $42.70 \pm 4.67 \mathrm{~kg} / \mathrm{m}^{2}$ (35.2$\left.51.4 \mathrm{~kg} / \mathrm{m}^{2}\right)$. Using DXA as the gold standard, the average percentage of fat at study onset was 49.53 $\pm 3.50 \%$ (42.0-55.7\%). The selected basic anthropometric data are summarized in Table I. The average body weight at 6 months after the operation was $91.20 \pm 17.23 \mathrm{~kg}(p<0.001)$, and the average BMI was $33.02 \pm 4.94 \mathrm{~kg} / \mathrm{m}^{2}(p<0.001)$. The average weight loss amounted to $26.49 \mathrm{~kg}$. The percentage of total body fat dropped from $49.53 \pm 3.50 \%$ to $43.63 \pm 5.31 \%$ 
Table I. Anthropometric characteristics of patients before and 3 and 6 months after sleeve gastrectomy. Statistical significance was compared between the pre-surgery status and the post-surgery follow-up examination results, 6 months after the operation

\begin{tabular}{|lcccccccc|}
\hline \multirow{2}{*}{ Parameter } & \multicolumn{2}{c}{ Pre-surgery } & \multicolumn{2}{c}{3 months after surgery } & \multicolumn{2}{c|}{6 months after surgery } & \multirow{2}{*}{ Value of $p$} \\
\cline { 2 - 7 } & Average & SD & Average & SD & Average & SD & \\
\hline Age [years] & 41.89 & 10.21 & 42.14 & 10.14 & 42.47 & 10.19 & - \\
\hline Weight [kg] & 117.69 & 17.05 & 98.34 & 18.30 & 91.2 & 17.23 & $<0.001$ \\
\hline BMl [kg/m²] & 42.70 & 4.67 & 35.71 & 5.24 & 33.02 & 4.94 & $<0.001$ \\
\hline Body fat [\%] & 49.53 & 3.50 & 46.64 & 4.77 & 43.63 & 5.31 & $<0.001$ \\
\hline Waist circumference $[\mathrm{cm}]$ & 112.86 & 9.79 & 100.03 & 11.16 & 96.0 & 10.47 & $<0.001$ \\
\hline
\end{tabular}

Table II. Evaluation of weight reduction based on the percentage excess weight loss and the percentage excess BMI loss

\begin{tabular}{|lccccc|}
\hline Parameter & \multicolumn{2}{c}{3 months after surgery } & \multicolumn{2}{c}{ 6 months after surgery } & Value of $p$ \\
\cline { 2 - 5 } & Average & SD & Average & SD & \\
\hline EWL $[\%]$ & 37.31 & 17.98 & 49.01 & 19.9 & $<0.001$ \\
\hline EBL $[\%]$ & 43.49 & 21.86 & 57.0 & 23.56 & $<0.001$ \\
\hline
\end{tabular}

of total weight. The excess weight loss (EWL) was $37.31 \%$ and $49.01 \%$ at 3 and 6 months after the operation, respectively. The excess $\mathrm{BMI}$ loss (EBL) was $43.49 \%$ and $57.0 \%$ at 3 and 6 months after the operation, respectively. The data of excess weight and BMI loss are summarized in Table II.

\section{Changes of the monitored parameters at 6 months after laparoscopic sleeve gastrectomy}

Serum concentrations of TG $(1.97 \mathrm{mmol} / \mathrm{l}$ to 1.31 $\mathrm{mmol} / \mathrm{l} ; p<0.001), \mathrm{HbA}_{1 \mathrm{c}}(4.03 \%$ to $3.59 \% ; p<0.001)$ and of C-peptide (1702.77 pmol/l to $1208.93 \mathrm{pmol} / \mathrm{l}$; $p<0.002)$ dropped significantly with a simultaneous significant increase of high-density lipoprotein cholesterol (HDL) levels from $1.29 \mathrm{mmol} / \mathrm{l}$ to $1.39 \mathrm{mmol} / \mathrm{l}$ $(p<0.025)$. Changes of LDL cholesterol, TC or fasting glucose were not statistically significant. See Table III for the dynamics of changes in the monitored biochemical parameters after LSG.

\section{Discussion}

Obesity, jointly with the proportion of fat tissue being close to $50 \%$, is among significant risk factors of cardiovascular and metabolic disorders. Six months after laparoscopic sleeve gastrectomy, not only were significant average weight reductions reported in the study group (body weight drop by $22.5 \%$ at EWL of $49.01 \%$ and at EBL of $57 \%$ ), but a dramatic reduction of fat tissue was also observed. Health risks associated with obesity increase with growing volumes of intra-abdominal adipose tissue. From this perspective, there has been a positive reduction in waist circumference of $16.86 \mathrm{~cm}$, observed in our study. In terms of success, DeAquino et al. [24] defines bariatric procedures as successful if patients demonstrate weight losses below $25 \%$ of their preoperative level, satisfactory if they lose $25-30 \%$ of their preoperative weight, and very good if the weight loss is over $30 \%$ of its total preoperative value. Consequently, our results of weight reduction can be evaluated as successful and comparable with the results of similar studies of patients after laparoscopic sleeve gastrectomy - see also Buchwald's et al. meta-analysis [25].

The main obesity-related metabolic risk factors of cardiovascular disease involve low serum HDL cholesterol levels with increased levels of TG and LDL cholesterol levels. During 6 month after the surgical intervention, significant changes in the lipid profile were reported, specifically an increase of HDL cholesterol $(p<0.025)$ and a decrease of TG $(p<0.001)$ lev- 
Table III. Parameters of lipid and glucose metabolism before and at 3 and 6 months after sleeve gastrectomy. Statistical significance was compared between the pre-surgery status and the post-surgery follow-up examination results, 6 months after the operation

\begin{tabular}{|c|c|c|c|c|c|c|c|}
\hline \multirow[t]{2}{*}{ Parameter } & \multicolumn{2}{|c|}{ Pre-surgery } & \multicolumn{2}{|c|}{3 months after surgery } & \multicolumn{2}{|c|}{6 months after surgery } & \multirow[t]{2}{*}{ Value of $p$} \\
\hline & Average & SD & Average & SD & Average & SD & \\
\hline Glucose [mmol/l] & 5.58 & 0.67 & 5.45 & 0.68 & 5.29 & 0.65 & NS \\
\hline $\mathrm{TC}[\mathrm{mmol} / \mathrm{l}]$ & 5.27 & 0.76 & 5.29 & 0.90 & 5.11 & 0.81 & NS \\
\hline $\mathrm{TG}[\mathrm{mmol} / \mathrm{l}]$ & 1.97 & 0.78 & 1.60 & 0.50 & 1.31 & 0.49 & $<0.001$ \\
\hline $\mathrm{HDL}[\mathrm{mmol} / \mathrm{l}]$ & 1.29 & 0.26 & 1.28 & 0.30 & 1.39 & 0.30 & $<0.025$ \\
\hline $\mathrm{LDL}[\mathrm{mmol} / \mathrm{l}]$ & 3.06 & 0.72 & 3.28 & 0.75 & 3.18 & 0.69 & NS \\
\hline $\mathrm{HbA}_{1 \mathrm{c}}[\%]$ & 4.03 & 0.48 & 3.54 & 0.34 & 3.59 & 0.39 & $<0.001$ \\
\hline C-peptide [pmol/l] & 1702.77 & 661.34 & 1286.89 & 783.97 & 1208.93 & 546.96 & $<0.002$ \\
\hline
\end{tabular}

Student's t-test at statistical significance of 0.05 was used; TC - total cholesterol, TG - triacylglycerols, HDL - high-density lipoprotein cholesterol, $L D L$ - low-density lipoprotein cholesterol, $\mathrm{HbA}_{1 c}-$ glycated hemoglobin

els. On the other hand, no statistically significant changes were reported in total or LDL cholesterol levels. Similar results were obtained by the team of Strain et al. [26] with approximately the same number of patients as in our study. One year after LSG, they reported a significant increase of HDL cholesterol levels, with a significant decrease of TG, while similarly as in our study - LDL and total cholesterol remained unchanged. Apart from changes in the lipid profile, changes in glucose metabolism parameters were found as well. The observed improvement of glycated hemoglobin and C-peptide levels was statistically significant. On the other hand, no changes were reported in fasting glucose levels. Similar conclusions were obtained by Wong et al. [27] in their observations during an open 9-month study in 37 patients during which both the lipid spectrum and glycated hemoglobin values were monitored. As in our study, they reported a significant decrease of glycated hemoglobin and improved parameters of lipid metabolism after LSG. But, compared with our results, they reported improvement not only of HDL and TG but also of TC and LDL cholesterol.

The interpretation of lipid spectrum changes is not an easy task. Despite relatively significant weight losses, connected with fat tissue reduction, TC decrease was not reported as statistically significant. Regarding the cardiovascular risks, the observed increased HDL cholesterol and decreased TG levels are fairly positive prognostic factors [28, 29]. Similar results were also obtained by Vidal et al. [30], with a significant improvement of lipid profile following LSG (improved hypertriglyceridemia in $80 \%$ of the group and increased HDL cholesterol in $50 \%$ of the group), including reduced risk for the metabolic syndrome. Apart from dyslipidemia, the positive changes after LSG include a therapeutic impact on other obesity-connected comorbidities; following the operation, more than $75 \%$ of patients demonstrated improved control of diabetes mellitus within 3 years $[31,32]$. Despite considerable and growing progress in the understanding of the presented issues, the mechanism responsible for improvement of dyslipidemia and insulin resistance remains unknown. Increased insulin sensitivity is usually associated with total weight loss and fat tissue reduction. On the other hand, certain authors emphasize the fact that an improvement of dyslipidemia and obesityrelated comorbidities is less dependent on weight loss, being rather attributable to hormonal changes after LSG [33]. In our group of patients, apart from the observed changes in lipid metabolism, changes of $\mathrm{HbA}_{1 \mathrm{c}}(p<0.001)$ and C-peptide levels $(p<0.002)$ were reported. On the other hand, no significant glycemia decrease was identified. Changes in the parameters of glucose metabolism were not so surprising. Recently, many studies have shown a positive effect of LSG on the metabolism of glucose. Peterli 
et al. [34] have proved that, 1 week following LSG, significant hormonal changes occur, being accompanied by increased insulin, GLP-1 and PY levels. Those changes, as well as decreased ghrelin levels, can be a guide to explain the changes after LSG. However, the precise mechanisms responsible for the changes are not yet completely understood [35]. One explanation for the effect of LSG on glucose metabolism is its influence on the production of insulinotropic GLP-1 hormone, secreted mainly by $L$ and $K$ intestinal cells in response to the presence of nutrients in the intestinal lumina. Metabolic interventions (mainly malabsorption) dramatically increase the secretion of certain hormones, usually in the proximal parts of the intestines, also intervening with the enteroinsular axis. However, the mere impact of incretins is perhaps not the only mechanism of the metabolic intervention effect. Vagal nerve stimulation is also highly accountable, as well as alterations of vagal signals, followed by the effects of gastric evacuation capability $[36,37]$.

\section{Conclusions}

A number of positive effects of sleeve gastrectomy were demonstrated, regarding body weight reduction, $\mathrm{BMI}$, waist circumference and excessive BMI loss. Six months after the operation, glucose homeostasis was improved, as reflected in the drop of $\mathrm{HbA}_{1 c}$ and $\mathrm{C}$-peptide levels. Moreover, the improved metabolism of lipids was accompanied by HDL cholesterol increase and lowered levels of triacylglycerols, while neither LDL cholesterol nor total cholesterol changed in any significant way.

The short follow-up period after the operation and the relatively low number of patients included in the study were potential limitations of the reported study. However, our results are comparable with those of other, recently published studies [23, 26, 38]. Despite the rather short-term monitoring period, our study did confirm that LSG not only influenced total weight loss and fat tissue reduction but also improved risk factors, mainly dyslipidemia.

\section{Acknowledgments}

The study was supported by grants from the CR Ministry of Education's budgets, allocated via the University of Ostrava under registration numbers of SGS2/LF/2011 and SGS10/LF/2012.

\section{References}

1. World Health Organization. Obesity. Preventing and Managing the Global Epidemic. World Health Organ Tech Rep Ser 2000; No. 894.

2. Obesity and overweight, Factsheet №311, Updated March 2011, Available at: http://www.who.int/mediacentre/factsheets/fs311/ en/ index.html

3. Matoulek M, Svačina Š, Lajka J. The incidence of obesity and its complications in the Czech Republic. Vnitr Lek 2010; 56: 1019-27.

4. Sullivan PW, Ghushchyan VH, Ben-Joseph R. The impact of obesity on diabetes, hyperlipidemia and hypertension in the United States. Qual Life Res 2008; 17: 1063-71.

5. Nguyen NT, Magno CP, Lane KT, et al. Association of hypertension, diabetes, dyslipidemia, and metabolic syndrome with obesity: findings from the National Health and Nutrition Examination Survey, 1999 to 2004. J Am Coll Surg 2008; 207: 928-34.

6. Stanowski E, Paśnik K. Bariatric surgery - the current state of knowledge. Videosurgery Miniinv 2008; 3: 71-86.

7. Ackroyd R, Mouiel J, Chevallier JM, et al. Cost-effectiveness and budget impact of obesity surgery in patients with type-2 diabetes in three European countries. Obes Surg 2006; 16: 1488-503.

8. Franz MJ, Van Wormer JJ, Crain AL, et al. Weight-loss out comes: a systematic review and meta-analysis of weight-loss clinical trials with a minimum 1-year follow-up. J Am Diet Assoc 2007; 107: 1755-67.

9. Dadan J, Iwacewicz, P, Hady HR. New approaches in bariatric surgery. Videosurgery Miniinv 2008; 3: 66-70.

10. Avenell A, Brown TJ, McGee MA, et al. What are the long-term benefits of weight reducing diets in adults? A systematic review of randomized controlled trials. J Hum Nutr Diet 2004; 17: 317-35.

11. Sjöström L. Bariatric surgery and reduction in morbidity and mortality: experiences from the SOS study. Int J Obes 2008; 32: S93-7.

12. Buchwald H, Oien DM. Metabolic/bariatric surgery worldwide 2008. Obes Sur 2009; 19: 1605-611.

13. Bose M, Oliván B, Teixeira J, et al. Do incretins play a role in there mission of type 2 diabetes after gastric bypass surgery: what are the evidence? Obes Surg 2009; 19: 217-29.

14. Wylezoł M, Paśnik K, Dąbrowiecki S. Polish recommendations for bariatric surgery. Videosurgery Miniinv 2009; 4: S5-8.

15. Fried M, Hainer V, Basdevant A, et al. Inter-disciplinary European guidelines on surgery of severe obesity. Int J Obes 2007; 31: 569-77.

16. Duda M, Gryga A, Czudek S, et al. Twenty years of minimally invasive surgery in the Czech Republic. Videosurgery Miniinv 2011; 6: 42-7.

17. Trybull A, Frask A, Michalik M. Sleeve gastrectomy. Videosurgery Miniinv 2008; 3: 205-9.

18. Hess DS, Hess DW. Biliopancreatic diversion with a duodenal switch. Obes Surg 1998; 8: 267-82.

19. Marceau P, Biron S, St Georges R, et al. Biliopancreatic diversion with gastrectomy as surgical treatment of morbid obesity. Obes Surg 1991; 1: 381-7.

20. Michalik M, Budziński R, Orłowski M, et al. Splenic infarction as a complication of laparoscopic sleeve gastrectomy. Videosurgery Miniinv 2011; 6: 92-8. 
21. Valderas JP, Irribarra V, Rubio L, et al. Effects of sleeve gastrectomy and medical treatment for obesity on glucagon-like peptide 1 levels and glucose homeostasis in non-diabetic subjects. Obes Surg 2011; 21: 902-9.

22. Langer FB, Hoda R, Bohdjalian A, et al. Sleeve gastrectomy and gastric banding: effects on plasma ghrelin levels. Obes Surg 2005; 15: 1024-9.

23. Fried M, Hainer V, Basdevant A, et al. Interdisciplinary European guidelines on surgery of severe obesity. Obes Facts 2008; 1: 52-9.

24. DeAquino LA, Pereira SE, de Souza Silva J, et al. Bariatric surgery: impact on body composition after Roux-en-Y gastric bypass. Obes Surg 2012; 22: 195-200.

25. Buchwald H, Avidor Y, Braunwald E, et al. Bariatric surgery: a systematic review and meta-analysis. JAMA 2004; 292: 1724-37.

26. Strain GW, Zhang F, Lei W, et al. Changes in lipid profiles in morbidly obese patients after laparoscopic sleeve gastrectomy (LSG). Obes Surg 2011; 21: 305-9.

27. Wong ATY, Chan DC, Armstrong J, et al. Effect of laparoscopic sleeve gastrectomy on elevated C-reactive protein and at heterogenic dyslipidemia in morbidly obese patients. Clin Biochem 2011; 44: 342-4.

28. Dixon JB, O'Brien PE. Lipid profile in the severely obese: changes with weight loss after lap-band surgery. Obes Res 2002; 10: 903-10.

29. Wolf AM, Beisiegel U. The effect of loss of excess weight on the metabolic risk factor after bariatric surgery in morbidly and super-obese patients. Obes Surg 2007; 17: 910-9.

30. Vidal J, Ibarzadal A, Romero F, et al. Type 2 diabetes mellitus and the metabolic syndrome following sleeve gastrectomy in severely obese subjects. Obes Surg 2008; 18: 1077-82.

31. Abbatini F, Rizzelo M, Casella G, et al. Long term effects of laparoscopic sleeve gastrectomy, gastric bypass, and adjustable gastric banding on type 2 diabetes. Surg Endosc 2010; 24: 1005-10.

32. Lee WJ, Chong K, Ser KH, et al. Gastric bypass vs. sleeve gastrectomy for type 2 diabetes mellitus. Arch Surg 2011; 146: 143-8.

33. Gugenheim J, lannelli A. What impact does laparoscopic sleeve gastrectomy have on lipid levels in patients with metabolic disease? J Clin Lipidol 2011; 6: 353-5.

34. Peterli, Wolnerhanssen B, Peters T, et al. Improvement in glucose metabolism after bariatric surgery comparison of laparoscopic Roux-en-Y gastric bypass and laparoscopic sleeve gastrectomy a prospective randomized trial. Ann Surg 2009; 250: 234-41

35. Ashrafian H, LeRoux CW, Darzi A, Athanasiou T. Effects of bariatric surgery on cardiovascular function. Circulation 2008; 118 2091-102.

36. Fried M, Ribaric G, Buchwald JN, et al. Metabolic surgery for the treatment of type 2 diabetes in patients with BMI $35 \mathrm{~kg} / \mathrm{m}^{2}$ : an integrative review of early studies. Obes Surg 2010; 20: 776-90.

37. Proczko-Markuszewska M, Kaska Ł, Stefaniak T, et al. Surgical treatment of a non-obese patient with type 2 diabetes - primary experience. A case report. Videosurgery Miniinv 2011; 6: 99-102.

38. Hakeam HA, O'Regan PJ, Salem AM, et al. Inhibition of C-reactive protein in morbidly obese patients after laparoscopic sleeve gastrectomy. Obes Surg 2009; 19: 456-60.

Received: 30.03 .2012 , revised: 26.09 .2012 , accepted: 9.10.2012 